\title{
Introduction to IJIMS Special Issue
}

\author{
Instrumental Development in IMS and IMS-MS
}

\author{
Herbert Hill
}

Received: 26 July 2011 / Accepted: 26 July 2011 /Published online: 4 August 2011

(C) Springer-Verlag 2011

The rapid growth in the utilization of IMS for analytical chemistry is due in no small part to innovation of instrumentation. The philosophical question of whether science is advanced by the development of analytical methods for specific applications of need or whether the need for specific applications is generated by the development of novel analytical methods is as old as the art of analysis. Articles presented in this double issue of the journal, which is dedicated to the development of instrumentation in ion mobility spectrometry and ion mobility spectrometry - mass spectrometry, fall into both categories. For example, instrumental developments independent of specific target applications that are presented in these issues include spherical FAIMS, paper spray ionization, ion separation by trapped
IMS, pulsed electron source, and the decomposition of overlapping plasmagram peaks. These developments may produce novel approaches to instrumentation with application to a wide variety of analyses. On the other hand, instrumental developments that are aimed at specific applications include IMS instrumentation for drug cleaning quality control and the analysis of nutritional supplements, developments in GC-IMS for the detection and measurement of VOCs on the space station, and the comprehensive software control of IMS. This collection of original research papers, technical reports and software applications clearly demonstrate the breadth that IMS and IMS-MS instrumentation brings to the science of analytical chemistry. I hope you find the collection interesting, useful and enlightening. Enjoy.
H. Hill $(\bowtie)$

Department of Chemistry, Washington State University,

Pullman, WA, USA

e-mail: hhhill@wsu.edu 